\title{
Review of Catastrophic Fires and Risk Communication, Ghana
}

\author{
Ishmael D. Norman ${ }^{12 *}$, Blandina M. Awiah², Moses K. Aikins ${ }^{3}$, Fred N. Binka ${ }^{4}$ \\ ${ }^{1}$ Department of Health Policy Planning and Management School of Public Health (Hohoe Campus), University \\ of Health and Allied Sciences, Volta Region, Ghana \\ ${ }^{2}$ The Institute for Security, Disaster and Emergency Studies, Cantonments, Accra, Ghana \\ ${ }^{3}$ Department of Health Policy Planning and Management School of Public Health, University of Ghana, Accra, \\ Ghana \\ ${ }^{4}$ University of Health and Allied Sciences, Volta Region, Ghana \\ Email: *ishmael_norman@yahoo.com, blandinaawiah@hotl.com, maikins57@yahoo.com, \\ fred.binka@gmail.com
}

Received 25 March 2015; accepted 26 May 2015; published 29 May 2015

Copyright (C) 2015 by authors and Scientific Research Publishing Inc.

This work is licensed under the Creative Commons Attribution International License (CC BY).

http://creativecommons.org/licenses/by/4.0/

(c) (i) Open Access

\begin{abstract}
Introduction: The incidence and prevalence of catastrophic fire outbreaks in Ghana appear to be very high. We wanted to review the data on the incidence and prevalence of catastrophic fires in all the administrative regions of Ghana in order to understand the situation better. It would also help to inform policy and interventions. Objective: We reviewed the statistics and other data of catastrophic fires in Ghana between 2004 and 2012. We identified the potential limitations for the existing national fire prevention system and provided suggestions for improvement. Method: We adopted the annual statistical data of the incidence of fire nationwide compiled by the National Fire Service "as is". We relied on the Service's field reports at the time of fire interventions and telephone and key informant interview to determine whether there was pre-event, event and post-event risk communication on the threat of fire within the affected sites. We also reviewed the National Emergency Master Plan, 1997; amended (2010) to assess whether it addressed fire emergencies. We conducted field visits to the Fire Service sub-stations within Accra City to assess the conditions on the ground. We also carried out documentary search on the internet to locate appropriate literature and summarized the findings into their respective units. Result: The result shows that catastrophic fire outbreak in Ghana occurred at least once a month at the cost of USD \$16 m per year between 2004 and 2012. There is no coordinated fire risk communication and advocacy, which may have led to the low risk perception in the population affected. Discussion: The recurrence of industrial and domestic fires in Ghana suggests that the population may have low risk perception, which requires intensified public education on risk in general. Conclusion: Residents in Ghana are confronted with the existential threat of fires in all their walks of lives, which needs to be addressed. The incidence and prevalence of fire risk in Ghana should be of interests to all.
\end{abstract}

*Corresponding author. 


\title{
Keywords
}

\author{
Risk Communications, Catastrophic Fires, Fire Emergencies Preparedness, Cost of Fire Damages, \\ Ghana
}

\section{Introduction}

Residents in Ghana appear to be confronted with the existential threat of fires in all their walks of lives, which needs to be addressed. This paper sought to show the incidence and prevalence of catastrophic fires in Ghana in order to understand the types of fires that the nation experienced. It was envisaged that the data and the analyses contained in this paper would enable the practitioners and authorities to design interventions for the mitigation, suppression and avoidance of fire outbreaks in Ghana. In general, due to the enormous increase in exposure of industrial assets and private property to extreme disaster events such as fires, for the first time in history, the world experienced three consecutive years, where annual economic losses exceeded $\$ 100$ billion. Such increases have happened on nine occasions including the last three years: 2010 (\$138 billion), 2011 (\$371 billion) and 2012 (\$138 billion). The increase has occurred despite there being no "mega-disaster such as a major urban earthquake" (Longworth, 2013). Disasters happen despite the best efforts of trained emergency personnel. Disasters are not bolts from the blue but a series of societal, communal, or individual mistakes, processes, and undertakings that lead to that one big disastrous event (Slovic, 2000; Fischhoff, 2002, 1977, 1975; Reason, 1990: p. 174; Norman, 1988: p. 140; Tversky \& Kahneman, 1974; cited in Fischhoff, 1975: p. 288). "Risk” is always socially constructed by humans and has no objective existence" (Quarrantelli, 2002: 1). Again, it is said that "all perceptions of risk, whether lay or expert, represent partial or selective views of the things and situations that threaten us" (Quarrantelli, 2002: 1-25). We are yet to find out whether the community in Ghana is afraid of the risk of fire and if so, what they are collectively doing to arrest the incidence and prevalence of fires in their various walks of lives.

In normal parlance, disaster is an event or an occurrence that causes great distress or concern. We take the definition of emergency from Ghana’s Emergency Powers Act 472 of 1994, § 5. It defines the state of emergency to include:

“...a natural disaster and any situation in which any action is taken or is immediately threatened to be taken by any person or body of persons which:

1) is calculated or likely to deprive the community of the essentials of life; or 2) renders necessary the taking of measures which are required for securing the public safety, the defense of Ghana and the maintenance of public order and supplies and services essential of the life of the community."

The generic definition of the state of emergency contained in the Emergency Powers Act is similar to the declaration of disastrous situation as defined in the Act 517 of 1996 of National Disaster Management Organization (1996), which states in Part 3, § 27 that disaster means any occurrence by which there is a serious disruption of general safety endangering the life and health of many people or large material interests which requires coordinated action by services of different disciplines and includes floods, earthquakes, drought, rainstorm, war, civil strife, and industrial accidents.

Although fire risks are not necessarily mentioned in the generic definition of emergencies, it is implied that fire risk is part of the existential threats to which the nation faces. The word "catastrophe" is defined to mean a sudden, extensive or notable disaster or event (Harper Collins Publishing, 2000). We define "catastrophic fire" as a sudden ignition of combustibles that incinerates uncontrollably despite the best efforts of fire rescue crew or the community and results in material loss of social assets.

\section{Risk Communication and Fire Emergencies}

Risk communication envisions a system encompassing the actual communication of imminent danger to the community and early warning system (Slovic, 2000; Glik, 2007). These form the set of capabilities needed to generate and disseminate timely and meaningful warning information to enable individuals, communities and organizations at risk of a hazard to prepare and to act appropriately and in sufficient time to reduce the possibility of harm or loss (UNISDR, 2009). It appears risk communication in fire emergencies in Ghana often lacks 
behind the emergency and mitigation. It also appears that pre-event and post-event risk communication is almost absent in the communities where there are recurrent fire outbreaks. Again, it seems when the communication is made it is always at the event stage where the attentions of both the public and the practitioners are perhaps, tuned elsewhere. Risk communication made under escalating situations, go largely unheeded (Brockner, 1992; Baird \& Thomas, 1985). In fire emergencies, the risk is high and the emotions and fear of people are also high. In such a situation, communicating either mitigation message, response plan and even evacuation and retraction of trapped persons must be direct and accurate (Glik, 2007; Brockner, 1992). The sense of urgency that the communicator of the risk may bring to the communication whiles at the same time assuring the public of safety depends on the communicator's antecedents and risk perception (Glik, 2007).

The risk perception of a body politic such as Ghana is established through learned social patterns and cultural relationship to risk (Perry \& Lindell, 1991; Slovic, 2000; Flynn et al., 1999). That is to say, there is a relationship between psychosocial background and risk perception (Fischhoff, 2002; Quarantelli, 1989).

\section{Emergency Management Organizations: Ghana National Fire Service}

For a given nation or community to be more resilient and better prepared to handle any type of emergency, that community has to devote a reasonable amount of time to map its vulnerabilities (Wayne-Blanchard, 2003). The importance of the disaster risk management organization and its leadership is critical for the coordination of both resources and personnel (Quarantelli, 1989; Drabek, 1985). The Ghana National Fire Service, NFS, it appears "... devotes most of its resources to response, rather than to community fire preparedness and readiness... and ... interventions”. Despite, “...the Service has trained over 65,000 community fire volunteers as of 2013” (Anaglatey, 2013).

Disaster management organizations practices involve the systematic process of using administrative plans and programs, standard operating procedures, organizational and operational skills and capacities to implement strategies, policies and improved coping skills and capacities in order to lessen the adverse impacts of hazards and the possibilities of disasters (UNISDR, 2009). Such modalities fall under what the UNISDR calls, Disaster Risk Management (DRM).

In order to achieve effective disaster risk reduction status, many researchers have proposed capacity building in the organization in terms of disaster/emergency management and administration. Disaster/Emergency Management, therefore, refers to a range of practices designed to deal with emergencies or disasters (NADMO Act 517, 1996). This involves policy making in four areas; namely mitigation, preparedness, response and recovery (Petak, 1985; Quarantelli, 1989).

Mitigation policies are those designed to prevent emergencies or to reduce their impact (Waugh Jr. \& Hy, 1990). Preparedness policies involve measures to increase a community's capability to respond effectively to emergencies (McEntire \& Myers, 2004). Response policies are those pertaining to the provision of assistance to victims during and immediately after an emergency (Petak, 1985). Recovery policies address issues related to community recuperation after a disaster such as debris removal, restoration of lifelines, etc. (Petak \& Atkisson, 1982). In this paper, we would show that the lack of a national risk communication program for fire risk reduction is incongruent to the legal framework on DRM. It is a contributory factor for the incidence of catastrophic fires in the nation.

\section{Method and Procedure}

We adopted the annual statistical data of fire events nationwide as compiled by the National Fire Service (NFS) for the period "as is" for analysis.

We also searched the PUBMED and Ghana Medical Journal databases. For our research question we used search combinations of "fire risk communication, Accra, only", "risk communication, Ghana", "examples of national risk communication, Ghana, only", "fire risk reduction apropos risk communication", "Insurance claims arising out of fires, Ghana, only", "Cause and effect of domestic fires, Ghana", "Incidence and Prevalence of fires, Ghana only".

The inclusion criteria were any reports (scholarly paper, opinion, editorial, book chapter, internal post-operations reports, annual reports) or investigations on fire outbreaks in the nation in which a branch of the National Fire Service apparatus participated or led its suppression. If such a report addressed the thematic areas of this topic such as fire emergency and suppression, emergency intervention, risk assessment and communication, it 
was included in the review (Brockner, 1992; Baird \& Thomas, 1985; Slovic, 2000; Fischhoff, 2002, 1977, 1975; NADMO Act 517, 1996; Reason, 1990: p. 174; Petak \& Atkisson, 1982; Norman, 1988: p. 140; Tversky \& Kahneman, 1974; cited in Fischhoff, 1975: p. 288).

We excluded reports that addressed day-to-day internal communications on operations that were not normally available to the public. Papers that dealt with disasters or considered the preparedness of disaster management organizations in general, but which did not address fire incidence and prevalence on the national level were not included (Holloway \& Roomoney, 2008; Pelling \& Wisner, 2008; Oteng-Ababio \& Sarpong, 2013). Amissah et al. (2010) was about forest fires in Ghana and so were Hawthorne (1994); Chandler et al. (1983); Korem (1985). Ghana, like most nations, is prone to many types of emergencies each year and a few incidences of disasters about every decade (Coppola, 2012).

We also conducted 25 telephone interviews and five key informant interviews to assess awareness with risk communication and fire risk preparedness in general.

A "grey literature" review was performed non-selectively. We conducted an overview of existing emergency preparedness plan of the nation to determine whether it was adequate. In this analysis, we used Accra City as a case study. In order to assess the preparedness plans of Accra City, we evaluated the available "National Disaster Management Plans" on the basis of national best practices. As a benchmark for national best practices, we reviewed the fire suppression ability of Kotoka International Airport, KIA against that of the National Fire Service for Accra City.

We assumed that since the fire preparedness plans of Kotoka International Airport was meant to cover the airport alone; it probably would be more efficiently drawn and rehearsed for field application. In this vein, we had assumed that the chances of the preparedness plans of KIA being superior to that of the National Master Plan prepared by NADMO for either the whole nation or Accra city was highly probable (KIA International Airport, 2006/2007). The Ghana National Fire Service is a critical stakeholder of NADMO. We considered the needs of KIA as an important international airport. The likelihood of fire at any airport is great considering the presence of highly flammable aviation fuel, other combustibles and the sheer volume of users. Despite these threats, KIA experiences nil to very low incidence of fire. We wanted to research the reasons for their apparent superior preparedness status to inform policy on revamping the national program. We chose 2004 as the base year for the review and limited ourselves to September 2012 as the cut-off point where data was available. We also searched the reference lists and notes of articles for additional information.

We found Thirty-five publications that met our inclusion criteria. Twenty-five were articles and 10 were reports. We assigned an overall score and identified the position taken in the publication or report in relation to our objectives. We scored $1=$ entirely relevant; $1 / 2=$ somewhat relevant and $0=$ not relevant at all. We rated them and the papers that received scores above 3.5 out of 5 in our evaluation were further analyzed. With the exception of the internal reports generated by the National Fire Service on the incidence of catastrophic fires in the nation and reports from the KIA emergency preparedness program, none of the papers focused on this topic (Oteng-Ababio \& Sarpong, 2013; Holloway \& Roomoney, 2008; Pelling \& Wisner, 2008; Amissah et al., 2010; Hawthorne, 1994; Chandler et al., 1983; Korem, 1985). Some reviewed biomass fires only, while others exclusively reviewed statistics on fires in Sub-Sahara Africa or conducted global assessment of fire management (Global Facility for Disaster Reduction and Recovery, 2002; Fire Management Global Assessment, 2007).

The data was disaggregated into domestic, industrial, vehicular, institutional, electrical, commercial, bush and other fires. We reviewed the reports written by the NFS at the time of the fires to determine whether there was Pre-event, Event and Post-event risk communication within the affected neighborhoods or industrial sites. We summarized the findings into their respective units, and interpreted them based upon our skills, knowledge and specialization in risk communication, public health and in disaster risk reduction.

\section{Results}

\subsection{Part A: Result from the Systematic Review of Annual Statistical Data by NFS}

\subsubsection{Incidence of Fire Emergencies for 2004}

We investigated the incidence of fire outbreaks in Ghana from 2004 to 2012. In 2004, the base year, there were 50 fire related injuries and 60 deaths out of a total of 2418 fires of various kinds. The cause of most of the deaths and injuries were due to smoke inhalation or to various degrees of burns. The more catastrophic injuries resulted in death at either the ignition point or later in the hospitals. Those injured or dead came from various socio- 
economic backgrounds and other demographics.

The total amount of losses in terms of property was GHCedis 14,303,061 which was in 2004, equal to US $\$ 14,303,061$ with a monthly average cost of destruction of social asset for that year to be US $\$ 1,191,921.8$. Doing the same analysis for 2005, we found that the average monthly cost for 2005 was USD $\$ 4.2 \mathrm{~m}$, which fell to USD \$626,607 in 2007 and USD \$663,214 in 2008. In 2006, however, the 2004 damage figure was almost doubled from US \$14,303,061 to US \$27,275,130 as shown in Table 1 below. (The rate of exchange of the Ghana Cedis to the US dollar wavered from US \$1 = GHC 1 between 2004 and 2006, and GHC 1.20 between 2007 and 2011 full years. In 2012, it was trading at about GHC 1.50 but then shot up thereafter (http://www.merbanstockbrokers.com, Merchant Bank, 2014).

\subsubsection{Cost of Salvage of Social Assets Vis-À-Vis Cost Of Damages}

In Table 2, we notice the total cost of damages set against the value of salvaged assets expressed in percentages to demonstrate the lack of resilience and ineffectiveness of the interventions in fire emergencies in Ghana. In each of the years under consideration, the salvaged assets did not represent more than $2 \%$ of the total cost of damage assets. This shows the near futility of the intervention measures to extinguish the fires. It also shows that once a hostile fire starts in Ghana, the chances of the fires becoming catastrophic are highly probable.

\subsubsection{Area with the Highest Fire Related Injuries and Death for 2004}

The Greater Accra region with the highest concentration of firemen, women and equipment suffered the most injuries and deaths, registering 43 injuries and 46 deaths in 2004. Accra City however continued to sustain the greatest losses totaling USD \$7.4 m for 2004 alone. All the deaths and injuries in the Greater Accra region were attributable to Accra City.

The national incidence of domestic fires was $43 \%$ of the total fire outbreaks of 2418 while industrial and commercial activities related fires registered $4.4 \%$ and $5.4 \%$ respectively. Bush fires had the second highest incidence $10.6 \%$ with institutional fires being the lowest at only $1 \%$, as indicated Table 3.

\subsubsection{Escalating Cost of Fire Destruction}

By 2005, the cost of damaged social asset by fire had risen from US \$14.3 million in 2004 to approximately US $\$ 50.6 \mathrm{~m}$ nationwide or USD \$4.2 m per month as summarized in Table 3 below. This excludes other disasters and emergencies such as flooding, drought, and health emergencies such as malaria, cholera and CSM. Even though there was a drop of about 3.5\% in the incidence of domestic fires and another $2 \%$ drop in Bush fires, there were significant gains in all sectors including industrial fires which rose from $4.4 \%$ in 2004 to $5.4 \%$ in 2005. Vehicular fires roses from almost 9\% in 2004 to $9.2 \%$ in actual sense. Institutional fires rose from $1 \%$ to $1.6 \%$ in real terms. The number of people injured in fires rose from 50 persons in 2004 to a whopping 295 persons in 2005, while the death toll dropped by 2 in 2005 to record 58 against the 60 of the previous year.

Again, Accra City recorded the highest one year climb of 612 out of a total of 2436 fires and which represents an increase of almost $9 \%$ over the previous year. Table 3 shows the rising frequency of fires for the same period.

\subsection{Part B and C: Desk Top Review of National Preparedness Plan against That of KIA}

\subsubsection{The 1997 Master Plan for Disaster and Emergency Management as Revised, 2010}

There exists on paper what appears to be a 'comprehensive' disaster preparedness plan for the known disaster types likely to impact the lives of the communities as well as the socio-economic climate of the nation. This is referred to as the "National Disaster Management Plan" (1997) and here after referenced as NDMP-97. The NDMP-97 was revised in 2010 by a team led by the National Disaster Management Organization (1997). The first observation about the plan is that it is too old. The Plan was prepared in 1997 but revised in 2010. Even so, it did not appear to have taken cognizance of the demands that would be exerted on interventions by the urban populations in the major cities such as Accra, Kumasi, and Tamale. Since the revision of the NDMO-97, Accra City, for example, has grown considerably in size in a characteristically unplanned manner coupled with incremental growth in population. This makes the city more complex in its diversity of activities and neighborhoods and thus more challenging to offer credible interventions in emergencies. This observation is common to just about all of the cities and urban centers in Ghana due to rapid urbanization.

The UN indicates that the annual urban growth rate in Sub-Saharan Africa is almost 5 percent, twice as high 
Table 1. Number of injuries, damages and deaths from fire from 2004 to 8: 2012.

\begin{tabular}{ccccc}
\hline \multicolumn{2}{c}{ Fatalities } & & & \\
Injury & Death & Year & Cost of damage (GHS) & Cost of salvage (GHS) \\
\hline 50 & 60 & 2004 & $14,303,060,267.60$ & - \\
295 & 58 & 2005 & $50,610,779,008.00$ & - \\
11 & 24 & 2006 & $27,275,130,454.75$ & $233,394.00$ \\
42 & 11 & 2007 & $7,519,279.76$ & $304,222.00$ \\
29 & 31 & 2008 & $7,958,570.75$ & $533,478.00$ \\
56 & 56 & 2009 & $6,988,292.52$ & $90,610.00$ \\
57 & 20 & 2010 & $360,027,775.57$ & $93,214.00$ \\
57 & 54 & 2011 & $7,506,763.08$ & $46,650.00$ \\
\hline 85 & 39 & Sept. 2012 & $6,973,766.66$ & \\
\hline
\end{tabular}

Table 2. Cost of fire damages set against cost of salvaged assets after fires.

\begin{tabular}{cccc}
\hline Year & Cost of damage (GHC) & Cost of salvage (GHC) & \\
2004 & $15,546,804,638.70$ & - & 0.92 \\
2005 & $55,011,716,313.04$ & - & 0.92 \\
2006 & $29,016,096,228.46$ & - & 0.94 \\
2007 & $7,832,583.08$ & $243,118.75$ & 0.96 \\
2008 & $7,169,883.56$ & $274,073.87$ & 1.11 \\
2009 & $4,753,940.49$ & $362,910.20$ & 1.47 \\
2010 & $248,295,017.63$ & $62,489.66$ & 1.45 \\
2011 & $4,781,377.76$ & $59,371.97$ & 1.57 \\
Sept. 2012 & $3,594,725.08$ & $24,046.39$ & 1.94 \\
\hline
\end{tabular}

Table 3. Frequency of Fire outbreaks 2004 to 2012.

\begin{tabular}{|c|c|c|c|c|c|c|c|c|c|}
\hline \multirow[b]{2}{*}{ Year } & \multicolumn{9}{|c|}{ Fire Outbreak } \\
\hline & Domestic & Industrial & Vehicular & Institutional & Electricals & Commercial & Bush & Others & Total \\
\hline 2004 & 1036 & 107 & 215 & 25 & 165 & 134 & 256 & 480 & 2418 \\
\hline 2005 & 955 & 130 & 225 & 38 & 179 & 177 & 216 & 516 & 2436 \\
\hline 2006 & 939 & 103 & 198 & 24 & 254 & 152 & 164 & 760 & 2594 \\
\hline 2007 & 1354 & 130 & 272 & 52 & 233 & 277 & 370 & 511 & 3199 \\
\hline 2008 & 1267 & 128 & 323 & 66 & 213 & 277 & 463 & 512 & 3249 \\
\hline 2009 & 1241 & 91 & 361 & 64 & 239 & 283 & 355 & 224 & 2858 \\
\hline 2010 & 1075 & 84 & 367 & 81 & 262 & 270 & 229 & 233 & 2601 \\
\hline 2011 & 1315 & 123 & 415 & 95 & 263 & 327 & 238 & 457 & 3233 \\
\hline $\begin{array}{l}\text { Sept. } \\
2012\end{array}$ & 1214 & 101 & 367 & 67 & 222 & 248 & 478 & 336 & 3033 \\
\hline Total & 10396 & 997 & 2743 & 512 & 2030 & 2145 & 2769 & 4029 & 25621 \\
\hline
\end{tabular}


as in Latin America and Asia (UNDESA, 2012). Sub-Saharan Africa (hereafter SSA) also has the world's largest proportion of urban residents living in slums, which today are home to 72 percent of urban Africa's citizens representing a total of some 187 million people. As more and more people seek a better life in towns and cities, partly as a result of climate change impacts on the solely rain-fed agriculture, the slum population in urban Africa is projected to double every 15 years in a process known as the "urbanization of poverty" (UNDESA (2012). African cities are thus confronted in the new Millennium with the problem of accommodating the rapidly growing urban populations in inclusive cities, providing them with adequate shelter and basic urban services, while ensuring environmental sustainability, as well as enhancing economic growth and development (UNISDR, Global Assessment Report 2013). The urban population of SSA is expected to grow from 298 million in 2010 to around 596 million in 2030 and 1069 million in 2050 (UNDESA, 2012).

Ghana's urban growth has been very unequal from the very start and can be characterized as urban primacy. Urban primacy connotes a situation where a few urban areas take up a significant chunk of the urban population. In 1970, the total urban population in Ghana was about 2.5 million, representing 29 per cent of the total population. Of this number, 1.5 million people (62\%) lived in fifteen urban areas with populations of more than 20,000, and accounted for about 18 per cent of the total population. Only two of the fifteen cities, Kumasi and Accra Metropolitan areas, had populations of more than 100,000. But by the year 2000, the contribution of these 15 urban areas to the total urban population has dropped from 61.8 per cent to 50.2 per cent, even though their share of the national population has increased from 17.9 to 22.0 per cent. On the other hand, the 15 largest localities in 2000 constituted 51.0 per cent of the urban population (22.3\% of total population), up from 50.2 per cent in 1960, an indication of substantial growth of smaller communities since 1960 (GSS, 2005, UN HABITAT, 2013). For there to be credible intervention plan of a nation such as Ghana's NDMP-97, the basic demographics of the nation and sheer numbers of the people in significant population centers must be taken into consideration as a matter of urgency. Additionally, there has been little or no update or follow-up research and re-assessment of the known hazards and their implications on the communities following a major event.

\subsubsection{The Legal Framework for the Enforcement of Fire Risk Reduction Measures}

The Ghana National Fire Service was established by Act 537, 1997 to give a broad objective of prevention and management of undesired fires and other related matters. While the GNFS trains fire volunteers in the vulnerable communities, home-owners receive hardly any fire prevention training at all. Public fire education is almost absent except during spectacular fire events where a great deal of destruction or deaths have occurred. The following demonstrates the reach of the law in reducing fire risk to the population:

1) Organize public fire education programs;

2) Create and sustain awareness of the hazards of fire;

3) Heighten the role of the individual in the prevention of fires;

4) Provide technical advice for building plans in respect of machinery and structural layouts to facilitate escape from fire, rescue operations and fire management;

5) Inspect and offer technical advice on fire extinguishers;

6) Co-ordinate and advice on the training of personnel in fire fighting departments institutions in the country;

7) Train and organize fire volunteer squads at the community level;

8) Offer rescue and evacuation services to those trapped by fire or in other emergency situations;

9) Undertake any other function in incidental to the objectives of the Service;

It appears the owners of private family dwellings are not aware of the requirement of the law that, they obtain technical advice from the service prior to building. In an informal telephone sampling of 25 homeowners known to the author, not a single one was aware of this legal requirement. They had their houses either self-built or constructed by a contractor without ever receiving any inputs from the fire Service.

\subsubsection{KIA as Example of National Best Practice in Fire Prevention}

The Kotoka International Airport, Accra was used as a national best practice in the evaluation of incidence and prevalence of catastrophic fires. Almost all the key informants we interviewed at KIA and at the Ghana Civil Aviations did not want to be quoted or credited with the assertions they made to us during our visit, due to the political nature of job retention in the civil service.

\section{a. Best practices of KIA observed}

1) It was found that although KIA is confronted with pockets of fire outbreaks such as aircraft engine fires. 
There are also minor runway parameter fires on about every month during the period under review due to encroachment of the unused parts of the runway by squatter urban farmers. Despite the occurrences of these events, the Rescue Fire Fighting Team was able to control and suppress the fire at the ignition point before it could spread.

2) During the investigation, it was found that the Rescue Fire Fighting Service (RFFS) of the Ghana Civil Aviation had well organized staff. They seemedto be well trained and to have good equipment (ISRP/ICAO, 2006).

3) We also found that the KIA hadan appreciable amount of usable extinguishing agents such as foams, dry chemical powders, halogenated hydrocarbons, water and carbon dioxide (Co2) to suppress fires at the aerodrome.

4) Fire Tenders at the aerodrome were in excellent condition and the maintenance protocol was strictly adhered to by the RFFS.

\section{b. The Ghana National Fire Service practices compared to that of KIA}

1) The Ghana National Fire Service on the other hand relied on water for the most part, to suppress fires irrespective of the type of combustibles involved in the outbreak. "Each type of fire requires its own suppressive agent. Although the base is water, it is not always advisable to use water alone" (Anaglatey, Personal Communications, 2013).

2) Additionally, the KIA personnel and equipment met international standards in terms of fire suppression skills (ICAO, 2006), a claim which the Ghana National Fire Service, perhaps, could not readily make.

3) We also found that unlike the GNFS, KIA emergency plans were coordinated with major stakeholders, area hospitals and clinics.

4) Additionally, it had a well defined and functioning Emergency Operating Procedures with role assignment and a physical and dedicated Emergency Operating Center to activate and manage emergency situations.

5) Again, although the National Fire Service also appears to have very dedicated staff, it is often reported by the agency itself that its equipment is too old and insufficient. For example, protective gear for extreme heat have to be shared during response to fire outbreaks and it is faced with the lack of water hydrants forthe many high rise and low rise buildings in Accra city and other areas of the nation.

6) In Accra City, for example, more than $80 \%$ of the fire sub-stations serving the suburbs did not have basic equipment such as working Fire Tenders to be able to respond to fire emergency call on their own without mobilizing Fire Tenders from other sub-stations. This phenomenon increases response time, delays critical intervention and may contribute to the spread of fires from the ignition point to other areas. Many lack personnel protective suits, breathing apparatus, rest rooms or areas, and oxygen tanks.

7) Many of the staff were exposed to occupational risks such as smoke inhalation, excessive exposure to heat and stress during interventions and response to fires, which may reduce their ability to work under strenuous conditions for an appreciably lengthy durations.

\section{Discussion and Conclusion}

We began with the assumption that the incidence and prevalence of catastrophic fire outbreaks in Ghana appeared to be very high. We believe that the data contained in this paper has borne out the fact that catastrophic fire events in Ghana were indeed high during the period under study, with cost running in the millions of dollars. We observed that between 2004 and 2012, fire destroyed property with the average recorded value over US \$16 $\mathrm{m}$ or (GHC 16,000,000) in Ghana annually. While US $\$ 16 \mathrm{~m}$ a year in damages to fire may seem like a paltry sum in terms of monetary value in comparison to damages caused by fire in the Western industrialized nations, for a developing nation, the loss of US \$16 m to fire annually is considerable. The question is why? Why hasn't government-private partnership addressed this menace? Perhaps, the answer is found in how the people perceive risk. The recurrence of both industrial and domestic fires in Ghana suggests that the population generally may have low risk perception and this may be mediated by cultural relativism of the people. Low risk perception is a decision maker's tendency to take or avoid risky undertaking. Others may describe such a population as having low risk propensity, where the decision maker's perception of risk inherent in a given situation is low. The population can also be said to be having low outcome expectancy. This is a subjective belief of the individual's ability to control a given situation irrespective of whether he can or cannot do so in actuality (Ganzach et al. 2008). Low risk perception and low risk propensity suggest detachment from reality on some level, which may color the judgment of the decision maker in relation to the risk. In such a situation, risk perception could be temporary 
in nature but not a sustained part of the mundane and ordinary lives of the community.

Given the frequency and the intensity of the spate of fires in traditional markets and in artisanal trading centers in Ghana, there may be some truth to the suspicion that, perhaps, the population may have low risk perception due to factors such as superstition, the lack of education, and the lack of knowledge and awareness of the various ignition agents within the close living quarters of the traders, market women and working spaces. Though highly publicized disaster and emergency events can temporarily increase risk perception, this tends to taper off over time and return to earlier levels with distancing from the event (Drabek, 1985; Nigg, 1982). The preponderance of the evidence on the incidence of fire outbreaks in the nation suggests that more needs to be done in the area of risk communication in order to create and sustain the awareness of the population about undesired fires and their consequences (Fischhoff, 2002).

\section{Recommendations}

1) We recommend to the Ministry of Interior through the National Fire Service that threats to fires undermine the national security of the nation and efforts should be made to resource the National Fire Service with the appropriate equipment just as the KIA Rescue and Fire outfit has been properly equipped.

2) We also recommend that the National Fire Service engages the communities more to reduce the incidence and prevalence of fires.

3) Lastly, the National Fire Service should develop a world class forensic unit to investigate all fires and to take appropriate action against suspects where there is sufficient probably cause for a prudent and reasonable fire investigator to conclude that a crime has been caused.

4) To the Ministry of Health through the Ghana Health Service, we recommend that each District Hospital should be provided with a trained medical officer and a team of nurses with the appropriate consumables and equipment for burns treatment. They should be trained in emergency medicine and treatment and in general emergency preparedness and response.

5) To the National Ambulance Unit, the fleet of ambulances should be equipped and the EMS crew should be trained in the handling of fire victims as first medical responders to be able to offer needed services during transfer and transportation of burn victims.

6) To the National Disaster Management Organization, we recommend that NDMP-97 as revised in 2010 needs further revision, taking into consideration the population of Ghana, the significant population centers and the anticipated needs of the population in case of catastrophic fire outbreak.

\section{References}

Amissah, L., Kyereh, B., \& Agyeman, V. K. (2010). Wildfire Incidence and Management in the Forest Transition Zone of Ghana: Farmers Perspective. Ghana Journal of Forestry, 26, 61-73.

Anaglatey, B. (2013). Strengthening Leadership in Disaster Resilience Program. Accra: Personal Communication, Practitioners' Workshop.

Baird, I. S., \& Thomas, H. (1985). Toward a Contingency Model of Strategic Risk Taking. Academy of Management Review, 10, 230-243.

Brockner, J. (1992). The Escalation of Commitment to a Failing Course of Action: Toward Theoretical Progress. The Academy of Management Review, 17, 39-61.

Chandler, C., Cherrey, P., Thomas, P., Trabaud, L., \& Williams, D. (1983). Fire in Forestry Vol. I. Forest Fire Behaviour and Effects. New York, NY: John Wiley and Sons Inc., 171-258.

Coppola, D. (2012). Introduction to International Disaster Management (1st ed.). Burlington, MA: Butterworth and Henienmann.

Drabek, T. E. (1985). Emergency Management: The Human Factor, Monograph Series. Emmitsburg, MD: National Emergency Training Center.

Emergency Powers Act 472 (1994). Accra: Assembly Printing Press.

Fire Management Global Assessment (2007). FAO/UN Forestry Paper, 2007, 1-135. http://www.fao.org/docrep/009/a0969e/a0969e00.HTM

Fischhoff, B. (1975). Hindsight Is Not Equal to Foresight: The Effect of Outcome Knowledge on Judgment under Uncertainty. Journal of Experimental Psychology: Human Perception and Performance, 1, 288-299.

http://dx.doi.org/10.1037/0096-1523.1.3.288 
Fischhoff, B. (1977). Perceived Informativeness of Facts. Journal of Experimental Psychology: Human Perception and Performance, 1, 349-358. http://dx.doi.org/10.1037/0096-1523.3.2.349

Fischhoff, B. (2002). Risk Perception, Risk Communication, Risk Taking. Journal of Psychology and Financial Markets, 3 , 102-111. http://dx.doi.org/10.1207/S15327760JPFM0302 05

Flynn, J., Slovic, P., Mertz, C. K., \& Carlisle, C. (1999). Public Support for Earthquake Risk Mitigation in Portland, Oregon. Risk Analysis, 19, 205-216. http://dx.doi.org/10.1111/j.1539-6924.1999.tb00400.x

Ganzach, Y., Ellis, S., Pazy, A., \& Ricci-Siag, T. (2008). On the Perception and Operationalization of Risk Perception. Journal of Judgment and Decision Making, 3, 317-324.

Ghana National Fire Service (1997). Act 537.

Glik, D. C. (2007). Risk Communication for Public Health Emergencies. Annual Review of Public Health, 28, 33-54. http://dx.doi.org/10.1146/annurev.publhealth.28.021406.144123

Global Facility for Disaster Reduction and Recovery, GFDRR (2002). World Bank, Washington DC.

Harper Collins Publishing (2000). Collins English Dictionary, Complete and Unabridged (10th ed.). London: William Collins Sons and Co, Ltd.

Hawthorne, W. D. (1994). Fire Damage and Forest Regeneration in Ghana. Forestry Inventory and Management Project of the Ghana Forestry Department, ODA Forestry Series No. 4, 1-18.

Holloway, A., \& Rooomey, R. (2008). Weathering the Storm: Participatory Risk Assessment for Informal Settlements. Cape Town: University of Cape Town, Periperi Publications.

International Civil Aviation Organization (ICAO) (2006). International Standards Recommended Practices, Airclaims/ 24913/VMC/6: 2: 2006, Airport Audit. ISRP, Vol. 1:118/ISRP, Annex 14, 1999. Accra: Aviation Library, Kotoka International Airport.

Korem, A. (1985). Bush Fire and Agricultural Development in Ghana. Accra: Ghana Publishing Corporation, 122-158.

Kotoka International Airport (2006/2007) Emergency Preparedness Plan and Procedures (pp. 1-98). Accra: Aviation Library, Kotoka International Airport.

Longworth, E. (2013). Press Release, International Strategy for Disaster Risk Secretariat, Nairobi, 14 $4^{\text {th }}$ March, 2013.

McEntire, D. A., \& Myers, A. (2004). Preparing Communities for Disasters: Issues and Processes for Government Readiness. Disaster Prevention and Management, 13, 140-152. http://dx.doi.org/10.1108/09653560410534289

Merchant Bank (2014) Inter-Bank Exchange, Ghana. http://www.merbanstockbrokers.com

National Disaster Management Organization (1996). Act 517 of 1996.

National Disaster Management Organization (1997). National Disaster Management Plan, 1997 as (Amended 2010). HQ, Kanda, Accra, Ghana.

Nigg, J. M. (1982). Awareness and Behavior: Public Response to Prediction Awareness. In T. F. Saarinen (Ed.), Perspectives on Increasing Hazard Awareness (p. 138). Boulder, CO: Institute of Behavioral Science, the University of Colorado.

Norman, D. (1988). The Psychology of Everyday Things. New York: Basic Books, 140.

Oteng-Ababio, M., \& Sarpong, A. O. (2013). Prevention Is Better than Cure: Assessing Ghana’s Preparedness (Capacity) for Disaster Management. Journal of Disaster Risk Studies, 5.

Pelling, M., \& Wisner, B. (Eds.) (2008). Disaster Risk Reduction: Cases from Urban Africa. London: Earthscan Publication.

Perry, R. W., \& Lindell, M. K. (1991). The Effects of Ethnicity on Evacuation Decision-Making. International Journal of Mass Emergencies and Disasters, 9, 47-68.

Petak, W. J. (1985). Emergency Management: A Challenge for Public Administration. Public Administration Review, 45, 3-6. http://dx.doi.org/10.2307/3134992

Petak, W. L., \& Atkinson, A. A. (1982). Natural Hazard Risk Assessment and Public Policy: Anticipating the Unexpected. New York: Springer-Verlag. http://dx.doi.org/10.1007/978-1-4612-5686-1

Quarantelli, E. L. (1989). How Individuals and Groups React during Disaster: Planning and Managing Implications for EMS Delivery. Preliminary Paper No. 138, Newark, DE: Disaster Research Center, University of Delaware.

Reason, J. (1990). Human Error. Cambridge: Cambridge University Press. http://dx.doi.org/10.1017/CBO9781139062367

Slovic, P. (2000). Informing and Educating the Public about Risk. In P. Slovic (Ed.), The Perception of Risk (pp. 192-198). Sterling, VA: Earthscan.

Tversky, A., \& Kahneman, D. (1974). Judgment under Uncertainty: Heuristics and Biases. Science, 185, 1124-1131. http://dx.doi.org/10.1126/science.185.4157.1124

United Nations Department of Economic and Social Affairs (UNDESA) (2012) World Population Prospects, 2010 Revision. http://esa.un.org/unpd/wpp/index.htm 
Waugh Jr., W. L., \& Hy, J. (Eds.) (1990). Introduction to Emergency Management. Westport, CT: Greenwood Publishing Group, 1-10.

Wayne-Blanchard, B. (2003). The New Role of Higher Education in Emergency Management. American Journal of Emergency Management, 1, 30-34. 